\title{
Effectiveness of hydrogen peroxide as auxiliary treatment for hospitalized COVID-19 patients in Brazil: preliminary results of a randomized double-blind clinical trial
}

\author{
Marielle Bazzo Di Domênico, Henrique Cesca, Thales Henrique Jincziwski Ponciano, \\ Renan Brandenburg dos Santos, Ulysses Lenz, Vinícius Picoli Antunes, \\ Vinicius Webber Godinho, Kauê Collares, Pedro Henrique Corazza \\ Graduate Program in Dentistry, Dental School, University of Passo Fundo, Passo Fundo, Brazil
}

OBJECTIVES: To evaluate the effectiveness of hydrogen peroxide $\left(\mathrm{H}_{2} \mathrm{O}_{2}\right)$ in the form of mouthwash and nasal spray as an auxiliary treatment for coronavirus disease 2019 (COVID-19).

METHODS: Forty hospitalized patients who tested positive for severe acute respiratory syndrome coronavirus 2 using a reverse-transcription polymerase chain reaction test were evaluated. They were randomly divided into an experimental group $\left(\mathrm{n}=20\right.$; gargling with $1.0 \% \mathrm{H}_{2} \mathrm{O}_{2}$ and nasal wash with $\left.0.5 \% \mathrm{H}_{2} \mathrm{O}_{2}\right)$ or a control group $(\mathrm{n}=20)$. The solutions were used for 7 days and the patients were monitored every 2 days, for a total of 8 days. At check-ups, patients were asked about their symptoms and possible adverse effects of the solutions. The presence and severity (mild, moderate, or severe) of symptoms were recorded. Data were compared using the Student test and the Fisher exact test $(\alpha=0.05)$.

RESULTS: There was no significant difference between the 2 groups in the length of hospital stay $(\mathrm{p}=0.65)$. The most frequent symptom on day 0 was coughing $(72.0 \%$ in the experimental group and $76.5 \%$ in the control group), which abated over time. There was no significant difference between the groups in the evaluated symptoms. Most (75.0\%) of the patients in the experimental group presented a reduction in dyspnea between days 0 and 2. Few patients reported adverse effects from the use of the solutions.

CONCLUSIONS: $\mathrm{H}_{2} \mathrm{O}_{2}$ as a mouthwash and nasal spray is safe to use. There is insufficient evidence to demonstrate that $\mathrm{H}_{2} \mathrm{O}_{2}$ is effective as an auxiliary treatment for hospitalized COVID-19 patients.

KEY WORDS: Hydrogen peroxide, COVID-19, SARS-CoV-2, Mouthwashes, Nasal sprays

\footnotetext{
Correspondence: Pedro Henrique Corazza

Graduate Program in Dentistry, Dental School, University of Passo Fundo, Campus I, BR 285 km 171, Passo Fundo 99001-970, Brazil

E-mail: pedrocorazza@upf.br

Received: Jan 20, 2021 / Accepted: May 1, 2021 / Published: May 1, 2021

This article is available from: https://e-epih.org/

(C) This is an open-access article distributed under the terms of the Creative Commons Attribution License (https://creativecommons.org/licenses/by/4.0/), which permits unrestricted use, distribution, and reproduction in any medium, provided the original work is properly cited.

(C) 2021, Korean Society of Epidemiology
}

\section{INTRODUCTION}

Since its emergence in Wuhan, China in December 2019, severe acute respiratory syndrome coronavirus 2 (SARS-CoV-2) has become one of the biggest problems of the modern era. The reasons for its exponential growth include its high transmissibility between individuals, whether directly (coughing, sneezing, and inhaling saliva droplets), or indirectly (contact with contaminated surfaces) [1]. Moreover, the very high number of undocumented and asymptomatic cases (potentially reaching $79 \%$ of cases) also increases its transmission [2]. The median incubation period of the virus is es- 
timated to be approximately 5 days (between 2 and 7 days), and $97.5 \%$ of the patients who develop symptoms will do so within 11.5 days of infection $[3,4]$. The median interval from symptom onset to hospitalization is 7 days (interquartile range, 3-9) [5]. According to a systematic review [6] that included 24,410 adults with coronavirus disease 2019 (COVID-19), the most prevalent symptom was fever (78\%), followed by coughing (57\%) and fatigue (31\%). Other less frequent symptoms were observed, such as hyposmia (25\%), dyspnea (23\%), myalgia (17\%), chills (17\%), wheezing $(17 \%)$, headache $(13 \%)$, sore throat $(12 \%)$, arthralgia (11\%), vertigo/dizziness (11\%), mental confusion (11\%), and diarrhea (10\%). Among hospitalized patients, the most common symptoms were fever (up to $90 \%$ of patients), dry cough (60-86\%), shortness of breath (53-80\%), fatigue (38\%), nausea/vomiting or diarrhea (15-39\%) and myalgia (15-44\%) [2,3,7-9]. The complications of COVID-19 include cardiac, brain, lung, liver, kidney, and coagulation system dysfunction. COVID-19 can also trigger cardiomyopathy, ventricular arrhythmias, and hemodynamic instability [10]. The most common comorbidities of hospitalized patients are hypertension (present in $48-57 \%$ of patients), diabetes (17-34\%), cardiovascular disease (21-28\%), chronic lung disease (4-10\%), chronic kidney disease (3-13\%), malignancy (6-8\%) and chronic liver disease $(<5 \%)[5,8,11]$.

Starting on the first days of contact, the virus remains in patients' upper airway, being detected in the saliva of $91.7 \%$ of those infected [12]. The oropharynx and nasopharynx have high viral loads $[13,14]$, and are the main site of replication and elimination of the virus during the course of the disease [15]. These regions are directly associated with the evolutionary process of COVID-19. Zou et al. [14] analyzed the viral load in the nose and throat of samples obtained from symptomatic and asymptomatic patients. Higher viral loads were detected soon after the onset of symptoms, and the loads were higher in the nose than in the throat. According to Herrera et al. [16], the oral viral load of SARS-CoV-2 was associated with the severity of COVID-19 and, therefore, a reduction of the oral viral load may be associated with a decrease in disease severity. Similarly, a decrease in the oral viral load would decrease the amount of virus expelled and reduce the risk of transmission. Thus, antiseptic mouthwashes could potentially be beneficial for infected patients, but clinical studies are needed to confirm this possibility.

Hydrogen peroxide $\left(\mathrm{H}_{2} \mathrm{O}_{2}\right)$ in low concentrations has been used for several purposes. It has been proven to be effective in decontaminating surfaces $[17,18]$, and has recently been used to decontaminate N95 respirators for reuse [19]. In dentistry and otorhinolaryngology, $\mathrm{H}_{2} \mathrm{O}_{2}$ has been used for tooth whitening and as an antiseptic and cleaning agent [20,21]; mucosal irritation is rare or absent, even after long periods of use [22,23]. The advantages of $\mathrm{H}_{2} \mathrm{O}_{2}$ include easy access, low cost, and a long history of use in dentistry. However, direct and prolonged contact (more than $30 \mathrm{~min}$ utes) with the mucosa can result in irritation [22,23], and high doses must be avoided, especially in patients with cardiovascular disorders [24]. $\mathrm{H}_{2} \mathrm{O}_{2}$ disrupts the lipid membranes of some viruses through the action of oxygen free radicals. Studies report that coronavirus 229E and other enveloped viruses can be inactivated at concentrations of around 0.5\% [17,18]. Caruso et al. [23] suggested using a mouthwash with $\mathrm{H}_{2} \mathrm{O}_{2}$ soon after the beginning of the first symptoms, or a positive diagnosis for SARS-CoV-2, for disinfection of the oral cavity, and nasal washing with spray twice a day.

Thus, the objective of the present study was to evaluate the effectiveness of $\mathrm{H}_{2} \mathrm{O}_{2}$ in the form of a mouthwash (1.0\%) and nasal spray $(0.5 \%)$ as an auxiliary treatment for hospitalized COVID-19 patients. The hypothesis was that the treatment would be effective for reducing the symptoms related to the disease.

\section{MATERIALS AND METHODS}

\section{Study design}

This study was a randomized, double-blind, parallel, placebocontrolled clinical trial to assess the effectiveness of gargling and nasal wash with $\mathrm{H}_{2} \mathrm{O}_{2}$ to reduce COVID-19 symptoms in adult hospitalized patients.

The study was registered in the Brazilian Registry of Clinical Trials (No. RBR-6sx3sz) and followed the CONSORT (Consolidated Standards of Reporting Trials) criteria for clinical studies (http://www.consort-statement.org/). The CONSORT flow diagram is presented in Figure 1.

\section{Patients}

The eligible patients $(n=40)$ were admitted to the hospital with COVID-19 symptoms, and who were at least 18 years old and reverse-transcription polymerase chain reaction (RT-PCR) positive for SARS-CoV-2. During the research period (July and August 2020), there were 5,208 confirmed cases of COVID-19 in Passo Fundo.

The eligibility criteria were: having tested positive for SARSCoV-2 and having received the diagnosis less than 3 days before the intervention, being hospitalized outside the intensive care unit, having the physical capacity to gargle and apply the nasal spray on their own, having moderate or mild COVID-19 symptoms, and agreeing to participate in the study.

\section{Randomization}

Patients who met the eligibility criteria were randomly divided into experimental (gargling with $1.0 \% \mathrm{H}_{2} \mathrm{O}_{2}$ and nasal wash with $0.5 \% \mathrm{H}_{2} \mathrm{O}_{2}$, both associated with a mint essence) or control (placebo with deionized water associated with a mint essence, administered in the same way as the experimental group). Twenty patients were included in each group, without any predictability of allocation. Each group had specific letters for their representation. A randomization list was generated through a randomization website (https://www.random.org/). The randomization list was transferred to individual, sealed, opaque, and non-translucent envelopes. The envelopes containing a letter were given to the research team, who did not know the meaning of each letter. The patient drew his or her group's envelope. 


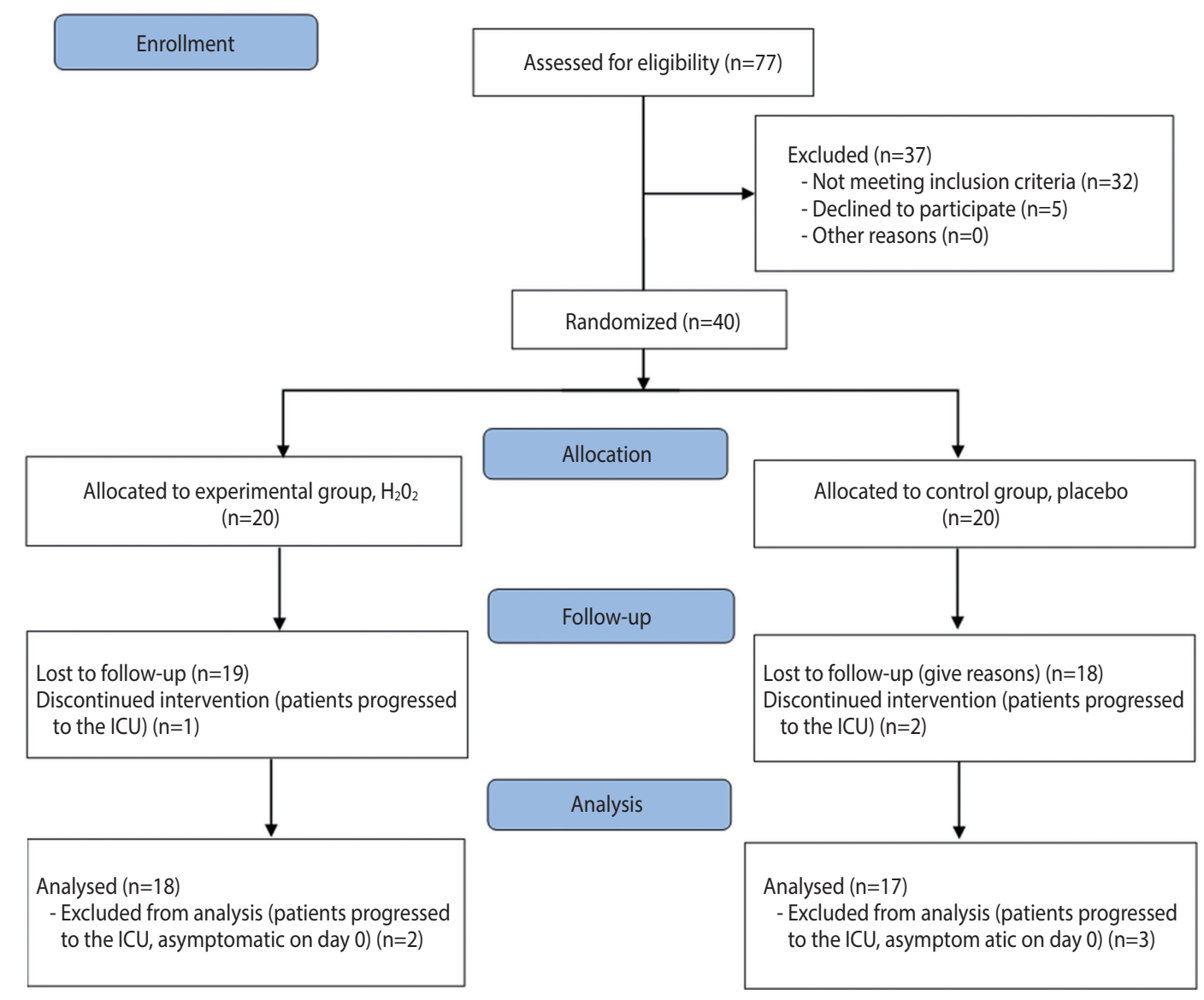

Figure 1. CONSORT (Consolidated Standards of Reporting Trials) flow diagram. $\mathrm{H}_{2} \mathrm{O}_{2}$, hydrogen peroxide; ICU, intensive care unit.

\section{Blinding}

The person responsible for manipulating the solution and a study researcher, who was not involved in the solution's distribution and assessment of outcomes, were aware of which letters corresponded to each group. Packages were prepared containing the appropriate treatments $\left(\mathrm{H}_{2} \mathrm{O}_{2}\right.$ or placebo), all with the same appearance, differentiated only by the letter corresponding to the group. The participants, researchers responsible for the solution's distribution and data tabulation, and the statistician were blinded.

\section{Researcher team training}

The research team was trained before the intervention. An approach guide was created and provided to the 2 researchers who contacted the patients. Therefore, the initial questions, instructions for using the solutions, randomization, and approach on the other days were standardized. A communication channel via WhatsApp was created for contact between the researchers (HC and THJP) and the research coordinator (PHC).

\section{Interventions}

The 2 groups ( $n=20)$ of the study were: (1) Experimental $(1.0 \%$ $\mathrm{H}_{2} \mathrm{O}_{2}$ for gargling and $0.5 \% \mathrm{H}_{2} \mathrm{O}_{2}$ for the nasal wash): Patients gargled with a solution composed of $1.0 \% \mathrm{H}_{2} \mathrm{O}_{2}$ and mint essence for 30 seconds, 3 times a day, for 7 days. One dose of the nasal spray was applied in each nostril, twice a day, for 7 days. The nasal solution was composed of $0.5 \% \mathrm{H}_{2} \mathrm{O}_{2}$ and mint essence. (2) Control (placebo): The control group gargled and applied the nasal spray in the same way as described for the experimental group. The placebo solution was composed of distilled water and mint essence.

A 10 -fold volumetric dilution of $3 \% \mathrm{H}_{2} \mathrm{O}_{2}(\mathrm{pH}=3.40)$ was prepared for the experimental group. One liter of $\mathrm{H}_{2} \mathrm{O}_{2}$ was diluted in $2 \mathrm{~L}$ of deionized water and $20 \mathrm{~mL}$ of essence (liquid mint extract), obtaining a $\mathrm{pH}$ of 4.33 and a solution with $1.0 \% \mathrm{H}_{2} \mathrm{O}_{2}$ for gargling. For the experimental nasal spray solution, $100 \mathrm{~mL}$ of the gargling solution was diluted in $100 \mathrm{~mL}$ of deionized water $(\mathrm{pH}=4.55)$. For the placebo gargling, $20 \mathrm{~mL}$ of essence was added to every $3 \mathrm{~L}$ of deionized water. For the placebo nasal spray, $100 \mathrm{~mL}$ of the placebo for gargling was diluted in $100 \mathrm{~mL}$ of deionized water.

\section{Data collection}

On day 0 (first contact), the patient was invited to participate in the research, and the kit composed of the gargling solution and nasal spray was provided. On the same day, individual variables 
Table 1. Demographic characteristics of patients at baseline, in absolute and relative values

\begin{tabular}{|c|c|c|c|}
\hline Characteristics & $\begin{array}{l}\text { Total } \\
(n=35)\end{array}$ & $\begin{array}{l}\text { Experimental } \\
\qquad(n=18)\end{array}$ & $\begin{array}{l}\text { Placebo } \\
(n=17)\end{array}$ \\
\hline \multicolumn{4}{|l|}{ Gender } \\
\hline Men & $22(62.9)$ & $9(40.9)$ & $13(59.1)$ \\
\hline Women & $13(37.1)$ & $9(69.2)$ & $4(30.8)$ \\
\hline \multicolumn{4}{|l|}{ Age (yr) } \\
\hline$\leq 35$ & $4(11.4)$ & $2(50.0)$ & $2(50.0)$ \\
\hline $36-59$ & $20(57.1)$ & $8(40.0)$ & $12(60.0)$ \\
\hline$\geq 60$ & $11(31.4)$ & $8(72.7)$ & $3(27.3)$ \\
\hline \multicolumn{4}{|l|}{ Race } \\
\hline White & $24(68.6)$ & $13(54.2)$ & $11(45.8)$ \\
\hline Non-White & $11(31.4)$ & $5(45.4)$ & $6(54.6)$ \\
\hline \multicolumn{4}{|l|}{ Education level } \\
\hline Completed high school & $30(85.7)$ & $16(53.3)$ & $14(46.7)$ \\
\hline $\begin{array}{l}\text { University education } \\
\text { (complete/incomplete) }\end{array}$ & $5(14.3)$ & $2(40.0)$ & $3(60.0)$ \\
\hline \multicolumn{4}{|l|}{ Family income (Brazilian reais) } \\
\hline$\leq 3,162.00$ & $22(62.9)$ & $9(40.9)$ & $13(59.1)$ \\
\hline$>3,162.00$ & $13(37.1)$ & $9(69.2)$ & $4(30.8)$ \\
\hline \multicolumn{4}{|c|}{ No. of people in the same residence } \\
\hline None & $3(8.6)$ & $1(33.3)$ & $2(66.7)$ \\
\hline 1 & $10(28.6)$ & $6(60.0)$ & $4(40.0)$ \\
\hline 2 & $8(22.9)$ & $4(50.0)$ & $4(50.0)$ \\
\hline 3 & $8(22.9)$ & $4(50.0)$ & $4(50.0)$ \\
\hline$\geq 4$ & $6(17.1)$ & $3(50.0)$ & $3(50.0)$ \\
\hline \multicolumn{4}{|c|}{ People who tested positive in the same residence } \\
\hline None & $24(70.6)$ & $11(45.8)$ & $13(54.2)$ \\
\hline 1 & $9(25.5)$ & $7(77.8)$ & $2(22.2)$ \\
\hline$\geq 2$ & $1(2.9)$ & $0(0.0)$ & $1(100)$ \\
\hline \multicolumn{4}{|l|}{ Comorbidities } \\
\hline Cardiac & $3(8.6)$ & $0(0.0)$ & $3(100)$ \\
\hline Respiratory & $3(8.6)$ & $3(100)$ & $0(0.0)$ \\
\hline Diabetes & $10(28.6)$ & $6(60.0)$ & $4(40.0)$ \\
\hline Hypertension & 17 (48.6) & $9(52.9)$ & $8(47.1)$ \\
\hline
\end{tabular}

Values are presented as number (\%).

were obtained from a questionnaire developed by the researchers. Socioeconomic and socio-demographic characteristics, comorbidities, and the patient's symptoms at baseline were recorded. (Table 1).

\section{Outcomes}

Patients were monitored in the hospital every 2 days, for 8 days, by the 2 trained researchers (for a total of 4 visits). If patients were discharged before the end of the survey, follow-up was carried out by phone. During follow-up visits, patients were asked about their symptoms with the question: "Do you have any of these symptoms? Fever, coughing, hyposmia, loss of taste, dyspnea, sore throat, or body pain?" If so, the severity of the symptom was asked (1, mild; 2 , moderate; or 3 , severe). The possible adverse effects of the solu- tion were also recorded with the question: "Did you have any of these symptoms after using the solution? A burning sensation in your mouth, a burning sensation in your throat, food tasting unpleasant after use, the feeling of having a thick tongue, or a burning sensation in your nose?" If so, the severity of the symptom was asked (1, mild; 2 , moderate; or 3, severe). For the clinical improvement variable, patients were considered to improve if, after 2 days of data collection, the patient did not present any of the COVID19 symptoms evaluated in the study. The patient's self-report was recorded in the form. Other clinical data were also recorded in the same form (discharge or transfer to the intensive care unit). All data were entered into an electronic database.

\section{Statistical analysis}

Stata version 14 (StataCorp., College Station, TX, USA) was used for data analysis. A descriptive analysis was first performed to determine the relative and absolute frequency of patient characteristics. The time between the start of treatment with the solutions and discharge, in each group, was compared using the Student $t$-test $(\alpha=0.05)$. The frequency of the symptoms-fever, coughing, hyposmia, loss of taste, dyspnea, sore throat, and body pain - was calculated on each day $(0,2,4,6$, and 8$)$. The proportion of individuals with relief from the symptoms of fever, coughing, dyspnea, and sore throat during days 0-2 and 2-4 were compared using the Fisher exact test $(\alpha=0.05)$. The possible adverse effects of the solutions were compared graphically.

Efficacy analysis was performed on an intention-to-treat basis, including all the patients who had undergone randomization. The time to clinical improvement was assessed after all patients had reached day 8 and was portrayed by a Kaplan-Meier plot. Hazard ratios (HRs) with $95 \%$ confidence intervals (CIs) were calculated by means of a Cox proportional hazards model.

\section{Ethics statement}

Ethical approval was obtained from the National Research Ethics Commission (CONEP, \#4.071.153) and from clinics hospital, the hospital involved in the research. All patients (or their legal representative) approved and signed the informed consent form.

\section{RESULTS}

When considering patients who discontinued the intervention and those who were asymptomatic on day 0 ( 2 in the experimental group and 3 in the control group), 35 patients were analyzed. Twenty-two (62.9\%) were women and $13(37.1 \%)$ were men. The predominant age of the patients included in the study was between 36 years and 59 years old (57.1\%). The most prevalent comorbidities were hypertension (48.6\%) and diabetes (28.6\%). Table 1 shows the characteristics of the patients at baseline.

The average time between the beginning of treatment and discharge was $3.86 \pm 1.60$ days in the experimental group, and $4.15 \pm$ 1.77 days in the control group; this difference was not statistically 
significant $(\mathrm{p}=0.65)$

The number of patients with each symptom on the evaluated days can be seen in Table 2. There were no reports of fever on day 0 among the patients in the present study. The most frequent symptom on day 0 was coughing $(72.2 \%$ in the experimental group and $76.5 \%$ in the control group), which considerably abated over time. On day $0,27.8 \%$ of the experimental group and $17.7 \%$ of the control group had a sore throat, which practically disappeared after day 2 . The frequency of symptoms is shown in Table 2.

Fever was excluded from the symptom relief assessment. The proportions of individuals with relief from coughing, dyspnea, and sore throat are shown in Table 3. There was no significant difference between the groups using the Fisher exact test for the symptoms of coughing $(\mathrm{p}=0.67)$, dyspnea $(\mathrm{p}=0.15)$, and sore throat $(\mathrm{p}=1.00)$. Seventy-five percent of the experimental group patients had relief for dyspnea between days 0 and 2 of the treatment.

Patients assigned to the $\mathrm{H}_{2} \mathrm{O}_{2}$ group did not present a different time to clinical improvement from that of patients assigned to the control group in the intention-to-treat population (median, 4 days vs. 4 days; HR for clinical improvement, 1.06 ; $95 \%$ CI, 0.42 to 2.68 ; $\mathrm{p}=0.90)$ (Figure 2).

Table 4 shows the frequency of adverse effects reported by patients on days 2, 4, and 6 of the study. Few patients reported adverse effects associated with the use of the solutions during treatment. The most common effects were a burning throat on day 2 (22.2\%), nasal burning on day $2(16.7 \%)$, and the feeling of a thick tongue on day $4(18.7 \%)$.

Table 2. Frequency of symptoms each day, in absolute and relative values

\begin{tabular}{|c|c|c|c|c|c|c|c|c|c|c|}
\hline \multirow{2}{*}{ Symptoms } & \multicolumn{2}{|c|}{ Day 0 (baseline) } & \multicolumn{2}{|c|}{ Day 2} & \multicolumn{2}{|c|}{ Day 4} & \multicolumn{2}{|c|}{ Day 6} & \multicolumn{2}{|c|}{ Day 8} \\
\hline & $\mathrm{H}_{2} \mathrm{O}_{2}$ & Control & $\mathrm{H}_{2} \mathrm{O}_{2}$ & Control & $\mathrm{H}_{2} \mathrm{O}_{2}$ & Control & $\mathrm{H}_{2} \mathrm{O}_{2}$ & Control & $\mathrm{H}_{2} \mathrm{O}_{2}$ & Control \\
\hline Fever & - & - & - & $1(6.3)$ & $1(5.6)$ & - & $1(5.6)$ & - & - & - \\
\hline Cough & $13(72.2)$ & $13(76.5)$ & $13(72.2)$ & $9(56.2)$ & $8(44.4)$ & $7(41.2)$ & $8(44.4)$ & $3(18.7)$ & $8(44.4)$ & $3(18.7)$ \\
\hline Hyposmia & $6(33.3)$ & $11(64.7)$ & $6(33.3)$ & $9(56.2)$ & $5(27.8)$ & $8(47.1)$ & $6(33.3)$ & $6(37.5)$ & $4(22.2)$ & $4(25.0)$ \\
\hline Loss of taste & $7(38.9)$ & $12(70.6)$ & $7(38.9)$ & $10(62.5)$ & $7(38.9)$ & $6(35.3)$ & $6(33.3)$ & $5(31.2)$ & $5(27.8)$ & $4(25.0)$ \\
\hline Dyspnea & $8(44.4)$ & $10(58.8)$ & $6(33.3)$ & $9(56.2)$ & $3(16.7)$ & $4(23.5)$ & $1(5.6)$ & $3(18.7)$ & - & $2(12.5)$ \\
\hline Sore throat & $5(27.8)$ & $3(17.7)$ & - & - & - & - & - & - & $1(5.6)$ & - \\
\hline Body pain & $3(16.7)$ & $5(29.4)$ & $2(11.1)$ & $3(18.7)$ & - & $3(17.6)$ & - & $2(12.5)$ & - & $1(6.2)$ \\
\hline
\end{tabular}

Values are presented as number (\%).

$\mathrm{H}_{2} \mathrm{O}_{2}$, hydrogen peroxide.

Table 3. Absolute value and rate of symptomatic individuals ${ }^{1}$

\begin{tabular}{|c|c|c|c|c|c|c|c|c|}
\hline \multirow{2}{*}{ Variables } & \multicolumn{2}{|c|}{ Total with symptoms on day 0} & \multicolumn{2}{|c|}{ Day 0-2 } & \multicolumn{2}{|c|}{ Day 2-4 } & \multicolumn{2}{|c|}{ Day 4-6 } \\
\hline & $\mathrm{H}_{2} \mathrm{O}_{2}$ & Control & $\mathrm{H}_{2} \mathrm{O}_{2}$ & Control & $\mathrm{H}_{2} \mathrm{O}_{2}$ & Control & $\mathrm{H}_{2} \mathrm{O}_{2}$ & Control \\
\hline Coughing & 13 & 13 & $4(30.8)$ & $7(53.8)$ & $6(46.1)$ & $5(38.5)$ & $1(7.7)$ & $2(15.4)$ \\
\hline Dyspnea & 8 & 10 & $6(75.0)$ & $3(30.0)$ & $2(25.0)$ & $7(70.0)$ & $2(25.0)$ & $1(10.0)$ \\
\hline Sore throat & 5 & 3 & $5(100)$ & $3(100)$ & $0(0.0)$ & $0(0.0)$ & $0(0.0)$ & $0(0.0)$ \\
\hline
\end{tabular}

Values are presented as number (\%).

$\mathrm{H}_{2} \mathrm{O}_{2}$, hydrogen peroxide.

'On day 0 who experienced relief (but not necessarily complete elimination) of the symptoms of coughing, dyspnea, and sore throat over the first 6 days, starting on day 0 .

Table 4. Frequency of adverse effects on each day: value and rate

\begin{tabular}{|c|c|c|c|c|c|c|}
\hline \multirow{2}{*}{ Variables } & \multicolumn{2}{|c|}{ Day 2} & \multicolumn{2}{|c|}{ Day 4} & \multicolumn{2}{|c|}{ Day 6} \\
\hline & $\mathrm{H}_{2} \mathrm{O}_{2}$ & Control & $\mathrm{H}_{2} \mathrm{O}_{2}$ & Control & $\mathrm{H}_{2} \mathrm{O}_{2}$ & Control \\
\hline Burning mouth & $1(5.6)$ & - & - & $1(5.9)$ & - & - \\
\hline Burning throat & $4(22.2)$ & $1(6.2)$ & - & $2(11.8)$ & $1(6.7)$ & - \\
\hline Unpleasant taste of food after use & - & - & - & - & - & - \\
\hline Feeling of thick tongue & - & - & $3(18.7)$ & - & $1(6.7)$ & - \\
\hline Perceptible change in mucosa & - & - & - & - & - & - \\
\hline Nasal burning & $3(16.7)$ & $1(6.2)$ & $2(12.5)$ & $1(6.2)$ & $1(6.7)$ & - \\
\hline
\end{tabular}

Values are presented as number (\%).

$\mathrm{H}_{2} \mathrm{O}_{2}$, hydrogen peroxide. 


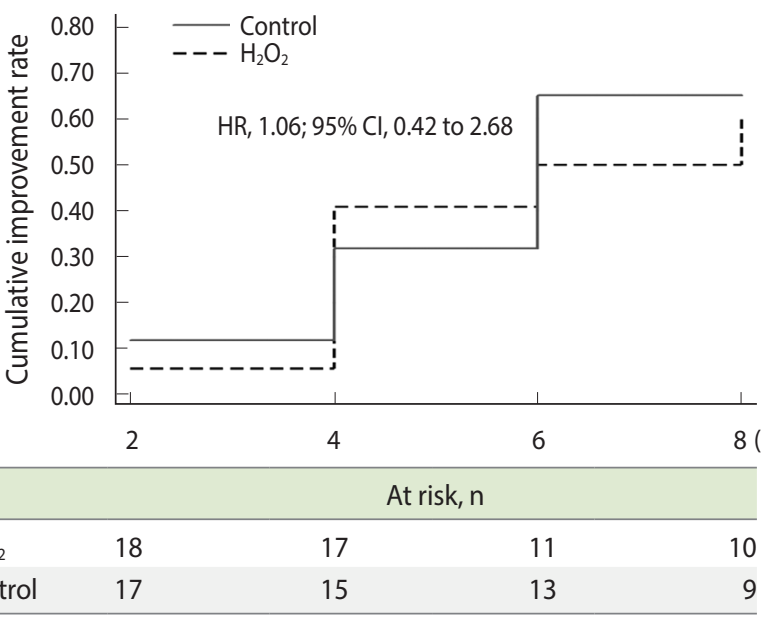

Figure 2. Time to clinical improvement in an intention-to-treat analysis. $\mathrm{H}_{2} \mathrm{O}_{2}$, hydrogen peroxide; $\mathrm{HR}$, hazard ratio; $\mathrm{Cl}$, confidence interval.

\section{DISCUSSION}

The present study evaluated 35 symptomatic patients hospitalized with COVID-19, aiming to verify the effectiveness of a $\mathrm{H}_{2} \mathrm{O}_{2}$ based mouthwash and nasal spray for COVID-19 symptom relief and time of hospitalization. The homogeneity between both groups in most characteristics reflects the effectiveness of the randomization. Originally, 20 patients were included in each group, but 18 patients were ultimately analyzed in the experimental group and 17 patients were analyzed in the control group, due to exclusions after the allocation. The slightly uneven distribution can be considered a limitation of this study. Despite having a small sample, the present study was able to indicate many points to build upon that could serve as the basis for new experiments related to this topic. The difficulty of conducting controlled clinical trials with COVID-19 patients during the greatest epidemic of the modern era must be highlighted. Inpatients in the COVID-19 ward already undergo a strict process of infection control and must fill out many forms, which hinders their willingness to agree to participate in research. In addition, hospital officials evaluated the project in detail before the researchers had access to the patients. Furthermore, the results of RT-PCR tests for SARS-CoV-2 carried out through the Brazilian public health system take quite a long time to be released. Since it was established that only patients who recently tested positive would be included in the research, the average between the onset of symptoms and the start of using the solutions was $10.72 \pm 2.68$ days. This was a problem since some symptoms, such as fever, were no longer present in the sample. In further research building upon the present study, symptomatic patients at the hospital and receiving home treatment will be included. The issue regarding the time between symptoms and the start of treatment is being solved by giving the solutions to patients who sought care even before the test result was released. However, we are now encountering the problem that approximately $80 \%$ of the samples are testing negative for COVID-19 and are thus being eliminated from the experiment.

The main comorbidities present in this study were hypertension (48.6\%) and diabetes (28.6\%). The data from the present study are similar to those of other recent experiments where the most prevalent comorbidities were also hypertension and diabetes [25-27]. These comorbidities are associated with the severity of COVID-19 and can significantly affect the prognosis of the disease [25,26]. Regarding transmission, 9 (25.5\%) patients evaluated in this study had at least 1 person living in the same house who had already tested positive for SARS-CoV-2. The persons close to the other patients had not been tested or had already tested negative for SARS-CoV-2. According to Guan et al. [3], the transmission of SARS-CoV-2 occurs mainly between family members, including relatives and friends living in the same residence, even when they are asymptomatic.

The most frequent symptom presented by the patients on day 0 was coughing $(74.3 \%)$, followed by loss of taste $(54.3 \%)$, dyspnea (51.4\%), hyposmia (48.6\%), sore throat (22.9\%), and body pain (22.9\%). In other studies [25,26], the most prevalent symptom was fever. With the exception of fever, the prevalence of other symptoms was similar to what was found in the literature. In a previous systematic review [25], the prevalence of fever, coughing, fatigue, and dyspnea symptoms was $85.6 \%, 65.7 \%, 42.4 \%$, and $21.4 \%$ respectively. In another study [26] the most prevalent clinical symptom was fever (91.3\%) followed by coughing (67.7\%), fatigue (51.0\%), and dyspnea (30.4\%). In the present study, all patients had some relief from symptoms during the 8 days, especially coughing, for both groups. In general, there was no difference in symptom relief between the 2 study groups. Loss of taste was the only oral manifestation evaluated by the present study, and was present in $54.3 \%$ of the sample on day 0 . Recent studies have reported other oral manifestations related to COVID-19 [28], such as ulcerative lesions on the tongue, palate, lip, and cheek. COVID tongue is an inflammatory disease that usually appears on the top and sides of the tongue. Some evidence suggests that it is associated with high levels of the inflammatory cytokine interleukin-6, which is positively regulated in severe COVID-19 disease [29-31].

The oral viral load may be associated with the severity of COVID-19 [16]; thus, antiseptics that have the ability to damage or destroy the lipid layer of the virus, such as $\mathrm{H}_{2} \mathrm{O}_{2}$, have the potential to reduce the viral load of infected individuals, thereby decreasing the severity of symptoms [16,32]. Considering this, and the possible relationship between the viral load and the symptoms of fever, coughing, dyspnea, and sore throat, the relief of these symptoms over days 0-2 and 2-4 was evaluated. Since there was no relevant sample size for fever, it was excluded from this analysis. Dyspnea abated for $75.0 \%$ of the experimental group patients between days 0 and 2; this relief occurred for $30.0 \%$ of the placebo group in the same period. However, this possible effect must be demonstrated with a larger sample size, since it was not statistically significant. Recently, a study finding an association between $\mathrm{H}_{2} \mathrm{O}_{2}$ mouthwash use and the viral load of COVID-19 patients was published [33], 
but the results seem inconclusive due to the small sample size. That study, which did not find effectiveness for $\mathrm{H}_{2} \mathrm{O}_{2}$ solution used only as a mouthwash, is different from the present study that used a mouthwash and nasal spray.

The solutions did not reduce hospitalization time, which was $3.86 \pm 1.60$ days for the experimental group and $4.15 \pm 1.77$ days for the control group after starting solution use. Both groups continued using the solutions for the predetermined time even after discharge.

$\mathrm{H}_{2} \mathrm{O}_{2}$ has been used in dentistry for more than 70 years. In some situations, $\mathrm{H}_{2} \mathrm{O}_{2}$ at concentrations below $3 \%$ was used daily for up to 6 years, causing occasional and transient irritating effects only in a small number of individuals [21]. In the present study, which used concentrations of $0.5 \%$ (nasal spray) and $1.0 \%$ (gargle), few patients reported adverse effects after using the solutions. The most common effects were a burning sensation in the throat and in the nose, demonstrating its safety for use in low concentrations for 7 days. Some effects, such as nasal burning, diminished over time. Thus, the prolonged use of $\mathrm{H}_{2} \mathrm{O}_{2}$ for a longer period than in the present study still deserves further research.

In conclusion, $\mathrm{H}_{2} \mathrm{O}_{2}$ as a mouthwash $(1.0 \%)$ and nasal spray $(0.5 \%)$ is safe to use by patients. Some improvement trends in dyspnea could be observed. However, there is insufficient evidence to demonstrate that $\mathrm{H}_{2} \mathrm{O}_{2}$ is effective as an auxiliary treatment for hospitalized COVID-19 patients.

\section{CONFLICT OF INTEREST}

The authors have no conflicts of interest to declare for this study.

\section{FUNDING}

Coordination for the Improvement of Higher Education Personnel (CAPES).

\section{ACKNOWLEDGEMENTS}

The authors are grateful to the Clinics Hospital from Passo Fundo, the City Hall of Passo Fundo. The authors are grateful to Dr. Jeferson Steffanello Piccin and Dr. Charise Dallazem Bertol for their help with the solutions.

\section{AUTHOR CONTRIBUTIONS}

Conceptualization: PHC, MBDD. Data curation: KC. Formal analysis: KC. Funding acquisition: MBDD. Methodology: HC, THJP, RBS, UL, VPA, VWG. Project administration: PHC, MBDD, HC. Writing - original draft: MBDD, PHC, HC. Writing - review \& editing: KC, THJP, RBS, UL, VPA, VWG, KC.

\section{ORCID}

Marielle Bazzo Di Domênico: https://orcid.org/0000-0002-21663052; Henrique Cesca: https://orcid.org/0000-0003-2751-0329; Thales Henrique Jincziwski Ponciano: https://orcid.org/0000-00023699-4225; Renan Brandenburg dos Santos: https://orcid.org/00000002-8188-480X; Ulysses Lenz: https://orcid.org/0000-0001-7382632X; Vinícius Picoli Antunes: https://orcid.org/0000-0003-30595095; Vinicius Webber Godinho: https://orcid.org/0000-0002-98970333; Kauê Collares: https://orcid.org/0000-0002-7276-1074; Pedro Henrique Corazza: https://orcid.org/0000-0001-9480-1607

\section{REFERENCES}

1. Lu CW, Liu XF, Jia ZF. 2019-nCoV transmission through the ocular surface must not be ignored. Lancet 2020;395:e39.

2. Li R, Pei S, Chen B, Song Y, Zhang T, Yang W, et al. Substantial undocumented infection facilitates the rapid dissemination of novel coronavirus (SARS-CoV-2). Science 2020;368:489-493.

3. Guan WJ, Ni ZY, Hu Y, Liang WH, Ou CQ, He JX, et al. Clinical characteristics of coronavirus disease 2019 in China. N Engl J Med 2020;382:1708-1720.

4. Lauer SA, Grantz KH, Bi Q, Jones FK, Zheng Q, Meredith HR, et al. The incubation period of coronavirus disease 2019 (COVID-19) from publicly reported confirmed cases: estimation and application. Ann Intern Med 2020;172:577-582.

5. Garg S, Kim L, Whitaker M, O’Halloran A, Cummings C, Holstein $\mathrm{R}$, et al. Hospitalization rates and characteristics of patients hospitalized with laboratory-confirmed coronavirus disease 2019 COVID-NET, 14 States, March 1-30, 2020. MMWR Morb Mortal Wkly Rep 2020;69:458-464.

6. Grant MC, Geoghegan L, Arbyn M, Mohammed Z, McGuinness L, Clarke EL, et al. The prevalence of symptoms in 24,410 adults infected by the novel coronavirus (SARS-CoV-2; COVID-19): a systematic review and meta-analysis of 148 studies from 9 countries. PLoS One 2020;15:e234765.

7. Docherty AB, Harrison EM, Green CA, Hardwick HE, Pius R, Norman L, et al. Features of 20133 UK patients in hospital with COVID-19 using the ISARIC WHO Clinical Characterisation Protocol: prospective observational cohort study. BMJ 2020;369: m1985.

8. Grasselli G, Zangrillo A, Zanella A, Antonelli M, Cabrini L, Castelli A, et al. Baseline characteristics and outcomes of 1591 patients infected with SARS-CoV-2 admitted to ICUs of the Lombardy region, Italy. JAMA 2020;323:1574-1581.

9. Huang C, Wang Y, Li X, Ren L, Zhao J, Hu Y, et al. Clinical features of patients infected with 2019 novel coronavirus in Wuhan, China. Lancet 2020;395:497-506.

10. Wiersinga WJ, Rhodes A, Cheng AC, Peacock SJ, Prescott HC. Pathophysiology, transmission, diagnosis, and treatment of coronavirus disease 2019 (COVID-19): a review. JAMA 2020;324: 782-793.

11. Richardson S, Hirsch JS, Narasimhan M, Crawford JM, McGinn 
T, Davidson KW, et al. Presenting characteristics, comorbidities, and outcomes among 5700 patients hospitalized with COVID-19 in the New York City area. JAMA 2020;323:2052-2059.

12. To KK, Tsang OT, Leung WS, Tam AR, Wu TC, Lung DC, et al. Temporal profiles of viral load in posterior oropharyngeal saliva samples and serum antibody responses during infection by SARSCoV-2: an observational cohort study. Lancet Infect Dis 2020;20: 565-574.

13. Peng X, Xu X, Li Y, Cheng L, Zhou X, Ren B. Transmission routes of 2019-nCoV and controls in dental practice. Int J Oral Sci 2020; 12:9.

14. Zou L, Ruan F, Huang M, Liang L, Huang H, Hong Z, et al. SARSCoV-2 viral load in upper respiratory specimens of infected patients. N Engl J Med 2020;382:1177-1179.

15. Wölfel R, Corman VM, Guggemos W, Seilmaier M, Zange S, Müller MA, et al. Virological assessment of hospitalized patients with COVID-2019. Nature 2020;581:465-469.

16. Herrera D, Serrano J, Roldán S, Sanz M. Is the oral cavity relevant in SARS-CoV-2 pandemic? Clin Oral Investig 2020;24:2925-2930.

17. Omidbakhsh N, Sattar SA. Broad-spectrum microbicidal activity, toxicologic assessment, and materials compatibility of a new generation of accelerated hydrogen peroxide-based environmental surface disinfectant. Am J Infect Control 2006;34:251-257.

18. Kampf G, Todt D, Pfaender S, Steinmann E. Persistence of coronaviruses on inanimate surfaces and their inactivation with biocidal agents. J Hosp Infect 2020;104:246-251.

19. Cheng VC, Wong SC, Kwan GS, Hui WT, Yuen KY. Disinfection of N95 respirators by ionized hydrogen peroxide during pandemic coronavirus disease 2019 (COVID-19) due to SARS-CoV-2. J Hosp Infect 2020;105:358-359.

20. Sharma K, Acharya S, Verma E, Singhal D, Singla N. Efficacy of chlorhexidine, hydrogen peroxide and tulsi extract mouthwash in reducing halitosis using spectrophotometric analysis: a randomized controlled trial. J Clin Exp Dent 2019;11:e457-e463.

21. Marshall MV, Cancro LP, Fischman SL. Hydrogen peroxide: a review of its use in dentistry. J Periodontol 1995;66:786-796.

22. Boyd RL. Effects on gingivitis of daily rinsing with $1.5 \% \mathrm{H} 2 \mathrm{O} 2$. J Clin Periodontol 1989;16:557-562.
23. Caruso AA, Del Prete A, Lazzarino AI. Hydrogen peroxide and viral infections: a literature review with research hypothesis definition in relation to the current COVID-19 pandemic. Med Hypotheses 2020;144:109910.

24. Byon CH, Heath JM, Chen Y. Redox signaling in cardiovascular pathophysiology: a focus on hydrogen peroxide and vascular smooth muscle cells. Redox Biol 2016;9:244-253.

25. Hu Y, Sun J, Dai Z, Deng H, Li X, Huang Q, et al. Prevalence and severity of corona virus disease 2019 (COVID-19): a systematic review and meta-analysis. J Clin Virol 2020;127:104371.

26. Yang J, Zheng Y, Gou X, Pu K, Chen Z, Guo Q, et al. Prevalence of comorbidities and its effects in patients infected with SARSCoV-2: a systematic review and meta-analysis. Int J Infect Dis 2020;94:91-95.

27. Zheng Z, Peng F, Xu B, Zhao J, Liu H, Peng J, et al. Risk factors of critical \& mortal COVID-19 cases: a systematic literature review and meta-analysis. J Infect 2020;81:e16-e25.

28. Favia G, Tempesta A, Barile G, Brienza N, Capodiferro S, Vestito MC, et al. COVID-19 symptomatic patients with oral lesions: clinical and histopathological study on 123 cases of the University Hospital Policlinic of Bari with a purpose of a new classification. J Clin Med 2021;10:757.

29. Amorim Dos Santos J, Normando AG, Carvalho da Silva RL, De Paula RM, Cembranel AC, Santos-Silva AR, et al. Oral mucosal lesions in a COVID-19 patient: new signs or secondary manifestations? Int J Infect Dis 2020;97:326-328.

30. Hathway RW. COVID tongue. Br Dent J 2021;230:114.

31. Riad A, Kassem I, Hockova B, Badrah M, Klugar M. Tongue ulcers associated with SARS-CoV-2 infection: a case series. Oral Dis 2020. doi: https://doi.org/10.1111/odi.13635.

32. O'Donnell VB, Thomas D, Stanton R, Maillard JY, Murphy RC, Jones SA, et al. Potential role of oral rinses targeting the viral lipid envelope in SARS-CoV-2 infection. Function (Oxf) 2020;1: zqaa002.

33. Gottsauner MJ, Michaelides I, Schmidt B, Scholz KJ, Buchalla W, Widbiller M, et al. A prospective clinical pilot study on the effects of a hydrogen peroxide mouthrinse on the intraoral viral load of SARS-CoV-2. Clin Oral Investig 2020;24:3707-3713. 